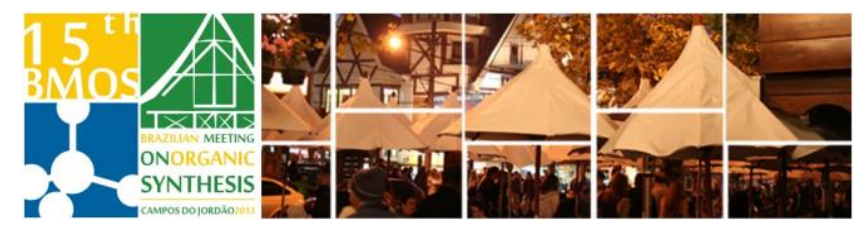

\title{
Synthesis and photophysical evaluations of $\beta$-fused Uracil- Porphyrin derivatives
}

\author{
Marta Akemi Fujita, Carla Marisa Brito Carvalho, Timothy John Brocksom and \\ Kleber Thiago de Oliveira*
}

Universidade Federal de São Carlos - UFSCar, Departamento de Química, 13565-905, São Carlos, SP,

Brazil.

*e-mail: kleber.oliveira@ufscar.br; www.lqbo.ufscar.br

Keywords: Porphyrin, uracyl, photodynamic therapy

\section{INTRODUCTION}

Porphyrin systems bearing fused rings have been a subject of intense research, since they constitute a viable approach to obtain new compounds with improved photophysical and photobiological properties. $^{1,2,3} \quad$ New $\beta$-fused uracil-porphyrin conjugates were synthesized by the tetramerization of uracil-pyrroles under acidic conditions, followed by oxidation. Complexation effects were also studied as well as aggregation in solution. Preliminary photophysical experiments were also performed in order to evaluate the potential of these new compounds for use in PDT, materials science or as fluorescent markers.

\section{RESULTS AND DISCUSSION}

Pyrrole 2 was prepared in 79\% yield from the compound $1^{4}$ according to the Vilsmeier-Haack methodology (Scheme 1). Reduction of $\mathbf{2}$ with $\mathrm{NaBH}_{4}$ in THF provided compound 3 (89\% yield). Several attempts to condense pyrrole 3 to porphyrin 4 were carried out with different acid catalysts and oxidation conditions. Success was finally obtained using TFA and then DDQ in $12.1 \%$ yield.

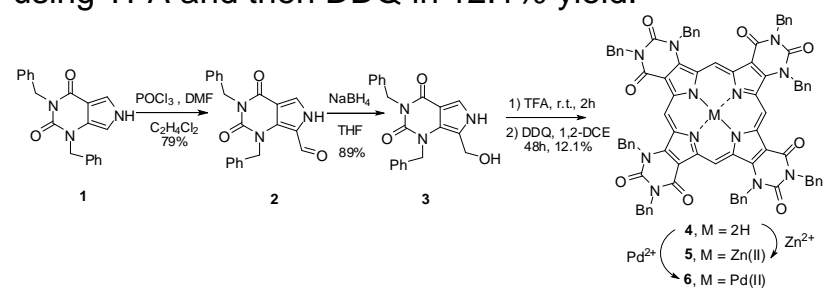

Scheme 1. Synthesis of $\beta$-uracil-porphyrin 4.

The synthesis of a novel class of $\beta$-fused uracilporphyrins prompted us to explore the facility of these macrocycles to complex different metals such as $\mathrm{Zn}(\mathrm{II})$ and $\mathrm{Pd}(\mathrm{II})$. Porphyrin 4 was reacted with $\mathrm{Zn}(\mathrm{OAc})_{2}$ and $\mathrm{Pd}(\mathrm{OAc})_{2}$ and the corresponding porphyrinic complexes 5 and $\mathbf{6}$ were obtained in 95 and $93 \%$ yields, respectively. All compounds were purified, and the structures confirmed by ${ }^{1} \mathrm{H}$ and ${ }^{13} \mathrm{C}$ NMR, HRMS and UV/Vis. Neither photobleaching decays nor aggregation were observed in THF solutions $(1-120 \mu \mathrm{M})$ for all three porphyrin derivatives. Studies on singlet oxygen generation (Figure 1) showed that $\mathrm{Pd}(\mathrm{II})$-porphyrin 6 was more effective when compared with the corresponding $\mathrm{Zn}(\mathrm{II})$-porphyrin 5 and the metal free porphyrin 4. The fluorescence emission quantum yields (Table 1) were also calculated for all three porphyrins.

Figure 1. DPBF absorbance decay at $410 \mathrm{~nm}$ in the presence of different photosensitizers.

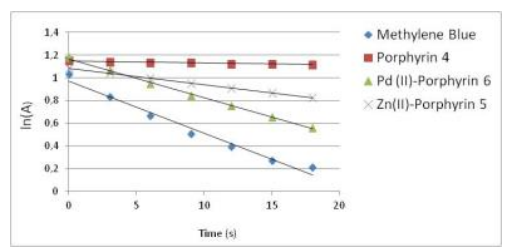

Table 1. The fluorescence quantum yields (Фf) of porphyrins 4, 5 and 6.

\begin{tabular}{cccc}
\hline \multirow{2}{*}{ Compound } & \multicolumn{2}{c}{ Fluorescence } & \multicolumn{1}{c}{$\lambda_{\max }[\mathrm{nm}]$} \\
& $\mathrm{Q}(0-0)$ & $\mathrm{Q}(0-1)$ & \\
\hline $\mathbf{4}$ & 671 & 735 & 0.150 \\
$\mathbf{5}$ & 630 & 671 & 0.006 \\
$\mathbf{6}$ & 672 & 729 & 0.070 \\
\hline
\end{tabular}

\section{CONCLUSION}

The synthesis of $\beta$-fused uracil-porphyrins starting from a functionalized pyrrole derivative was successfully accomplished. The new porphyrin derivatives demonstrated their potential in porphyrin chemistry, considering their photophysical parameters and related potential applications.

\section{ACKNOWLEDGEMENTS}

The authors thank FAPESP (2013/06532-4, 2012/04964-1, 2011/13993-2, 2011/17177-5), CNPq and CAPES for financial support and scholarships.

\section{REFERENCES}

${ }^{1}$ Carvalho, C.M.B; Brocksom, T.J.; de Oliveira, K.T. Chem. Soc. Rev. 2013, 42, 3302-3317.

${ }^{2}$ Vicente, M.G.H.; Smith, K.M. J. Porphyrins Phthalocyanines. 2004, 87, 26-42.

${ }^{3}$ Carvalho, C.M.B.; Neves, M.G.P.M.S.; Tomé, A.C.; Paz, F.A.A.; Silva

A.M.S.; Cavaleiro, J.A.S. Org. Lett. 2011, 13, 130-133.

${ }^{4}$ Carvalho, C.M.B; Fujita, M. A.; Brocksom, T.J.; de Oliveira, K.T.; 2013,

Tetrahedron, submitted. 